\section{Fenomenologia da visceralidade. Notas sobre o impacto das tecnologias de visualização médica na corporeidade}

\author{
Phenomenology of viscerality: the impact \\ of medical imaging technologies on corporeality
}

Francisco Ortega ${ }^{1}$

\section{Introdução}

This article deals with the phenomenological dimension of the inner body in light of the success of new medical imaging technologies outside the biomedical field itself. The new technologies contribute not only to the disembodiment of subjectivity, but also to the virtualization and objectification of corporeality. They neglect the constitutive subjective dimension of the living body. The article investigates this fundamental dimension of corporeality, ungraspable through medical imaging.

Technological Development; Diagnostic Imaging; Diagnostic Techniques and Procedures
O fascínio crescente pelas novas tecnologias de visualização médica do corpo extrapola o campo estritamente biomédico, atingindo os campos sócio-político e jurídico. Na cultura popular as imagens médicas exercem também uma atração singular. Mesmo quem nunca tenha se submetido a uma tomografia computadorizada ou a uma ressonância magnética se encanta com as imagens médicas na televisão, na tela de computador ou nas revistas de divulgação. As imagens coloridas de cérebros em funcionamento obtidas por PET-scanners tornaram-se tão populares como os retratos de Marilyn Monroe ou Mao Tsé Tung realizados por Andy Warhol, com os quais guardam uma certa semelhança cromática. O sucesso dessas tecnologias tem dado uma relevância ao interior do corpo humano que não encontra precedentes nas nossas sociedades. Meu objetivo é explorar as modificações na corporeidade resultantes da crescente visualização. O processo de tornar visível o invisível, o interior do corpo, possibilitado pelas novas tecnologias, deve ser entendido dentro de uma transformação cultural e social mais geral, cuja característica principal é a importância dada à corporeidade na descrição e explicação dos processos psíquicos e subjetivos.

O texto pretende indagar acerca do impacto na corporeidade das tecnologias de visualização. Não se pode ignorar as conseqüências 
epistemológicas, antropológicas e sócio-culturais, para além dos benefícios clínicos e terapêuticos decorrente do uso das novas tecnologias médicas, dessa obsessão com a visualização do invisível. As novas tecnologias estão contribuindo para a desincorporação da subjetividade e para a virtualização e objetivação da corporeidade, tornando obsoleto o corpo. A atração exercida pelas tecnologias de visualização está ligada, na minha opinião, ao fato de o interior do corpo escapar de minha apreensão subjetiva e fenomenológica. A visceralidade constitui uma dimensão corporal que é por natureza recessiva e ausente, que foge de minha percepção direta e que é, no entanto, constitutiva da corporeidade. É a essa angustia provocada por essa ambivalência constitutiva que as tecnologias tentam responder, pois o visceral ameaça o projeto biomédico de constituição de um conhecimento objetivo e causal do corpo. Porém, esse conhecimento objetivo não coincide fenomenologicamente com a sua experiência subjetiva. A análise fenomenológica do visceral realizada neste artigo pretende mostrar como essa dimensão constitutiva da corporeidade humana escapa das tentativas de objetivação das tecnologias de visualização médica.

\section{Ver o invisível}

Em seu último livro, publicado postumamente em 1978, a filósofa Hannah Arendt faz uma observação curiosa sobre o interior do corpo humano. Os "órgãos internos", afirma, "nunca constituem uma visão agradável; uma vez forçados a aparecer, dão a impressão de ter sido agrupados impacientemente e, a não ser quando deformados por uma doença ou anormalidade peculiar, parecem indiferenciados; nem mesmo as várias espécies animais - quanto mais os indivíduos - são facilmente distinguidos pela simples inspeção das vísceras" 1 (p. 29). A data é importante, pois dista quase um século da descoberta dos raios X por Roentgen em 1895, que catapultou o interior do corpo para o centro do interesse, não só no âmbito estritamente biomédico, mas na esfera sócio-cultural mais ampla. Nesse século, o entusiasmo por ver o invisível conserva-se vivo entre cientistas, médicos, advogados, artistas e o público leigo, crescendo com cada nova descoberta, sempre acompanhada de extensa cobertura midiática. Mas se, como nos lembra novamente Arendt 1, a visão do interior do corpo nunca é " $u m a$ visão agradável" 1 (p. 29), constituindo uma "monótona mesmice e feiúra penetrante” 1 (p. 35), em contraste com a "enorme variedade e rique- za da conduta humana pública" 1 (p. 35), por que essa obsessão com tornar visível o invisível? Por que trazer à luz o que deve permanecer oculto para “impedir sua exposição à luz de um mundo de aparências" 1 (p. 29)? Pois "se esse interior aparecesse, todos nós pareceríamos iguais" 1 (p. 29). Nos anos 70, Arendt podia escrever que "por dentro todos somos semelhantes, imutáveis, a não ser à custa do funcionamento de nossos órgãos psíquicos e corporais ou, inversamente, de uma intervenção feita com o propósito de remover alguma disfunção" 1 (p. 37). Essa afirmação deve ser hoje, no entanto, contextualizada. Diversos exemplos entre os quais podemos mencionar a "arte anatômica" de Gunther von Hagens e seus cadáveres plastinados e a "arte carnal” da artista performática Orlan - com suas numerosas cirurgias plásticas que visam a vincular o self interior e exterior e que acontecem como performances com coreografia, música, decorações especiais e sendo tudo gravado em vídeo e transmitido pela Web - mostram que o interior do corpo está sendo colonizado, não só pelas técnicas de visualização, mas também como superfície de inscrição para tentativas de singularização. Quando esse interior adquire a visibilidade que possui na nossa cultura, aparecem tentativas de dar uma identidade, uma marca singular a esse espaço em si homogêneo e opaco.

Para além desses exemplos extremos e um tanto bizarros caberia se perguntar - considerando que "por dentro somos todos semelhantes" como nos lembra a filósofa alemã - se não estaríamos abdicando de nossa individualidade e singularidade na nossa vontade de visualizar o interior do corpo presente na racionalidade biomédica ocidental e suas sofisticadas tecnologias de visualização. Acredito que antes de tentar obter uma resposta a essas perguntas devemos colocar as questões no contexto das transformações sócio-culturais das últimas décadas, às quais tenho me referido em outros lugares 2,3 , e cuja característica principal é a importância dada ao corpo e aos fenômenos corporais na descrição e explicação dos processos psíquicos e subjetivos.

\section{Corpo construído versus corpo material}

Tematizar os pressupostos epistemológicos e fenomenológicos presentes nos debates acerca da visualização médica do corpo pressupõe uma determinada noção de corporeidade, pois ao final, que corpo é esse que está sendo visualizado? Um "dado biológico", "uma construção discursiva”? Sem pretender entrar no atual de- 
bate sobre a natureza da corporeidade, que exigiria um trabalho independente ultrapassando os limites e objetivos deste artigo, devo fazer algumas breves considerações a respeito. A maioria dos estudiosos voltados nos últimos anos para questões da história da visualização do corpo e das representações anatômicas especialmente nos estudos feministas e sobre gays e lésbicas - compartilham uma posição teórica semelhante, que tenta problematizar a caracterização do corpo como um dado "natural" e critica a história da medicina e da ciência enquanto história de como e quando o corpo "real" foi descoberto. A naturalização constitui uma estratégia poderosa de submissão, como Foucault 4 tem freqüentemente insistido e que não deve ser menosprezada. "Desde o século XVIII o conceito de corpo construído anatômica e fisiologicamente", nos lembra a historiadora Barbara Duden 5 (p. 20), "foi cientificamente dotado da aparência de ser um fenômeno natural, enquanto que, ao mesmo tempo, foi tornado invisível como criação social". Trata-se de uma opinião com a qual pode-se concordar e na qual não vejo nenhum problema. Minha dificuldade é com afirmações que amiúde acompanham a posição anterior. Tomo como exemplo a de Alan Petersen 6, que - em um trabalho recente sobre construções anatômicas do corpo - ao "enfatizar o poder das práticas representativas da biomedicina, e mais especificamente da anatomia, de modelar nossa compreensão 'do corpo' como uma entidade material", parte do problemático pressuposto de que “'o corpo'é construído discursivamente, e que sua própria materialidade é um produto do poder". A questão da materialidade como efeito de poder ou como performatividade é lançada por Judith Butler no seu livro Bodies That Matter 7 . Nesse livro, a autora reage às criticas feitas ao seu livro anterior Gender Trouble 8, no qual a materialidade do corpo era negada. A meu ver a posição de Butler pode ter se tornado mais sofisticada, mas permanece nos seus pressupostos básicos de negar a materialidade, a qual é agora "o efeito mais produtivo do poder" 7 (p. 2).

Concordar com a primeira posição não implica necessariamente aceitar a segunda, a qual, a meu ver, não apenas é errada, mas se adequa à visão descarnada da corporeidade fornecida pelas novas tecnologias de visualização. Em poucas palavras, acredito que posições teóricas que afirmam a construção discursiva do corpo e neguem a sua materialidade fornecem o substrato teórico para as novas tecnologias médicas, avanços nas áreas de inteligência artificial e realidade virtual, entre outros, com sua afirmação da construção, virtualização e obso- lescência do corpo vivido. Em contrapartida, posições que considerem a experiência subjetiva do corpo, a nossa "corporificação", possuem, a meu ver, uma maior vantagem epistemológica e ética na hora de analisar os efeitos na corporeidade e na subjetividade das tecnologias de visualização médica do corpo. Nestas últimas, que podemos chamar de posições "ecológicas”, o corpo e o ambiente são indissociáveis. Eles são experienciados simultaneamente como um horizonte insuperável e o corpo aparece como o sujeito material do mundo. Ou seja, o corpo não é apenas uma coisa material entre outras coisas materiais no mundo, mas é, sobretudo, a coisa material, cuja capacidade de mover-se constitui e define a totalidade do campo da experiência no qual qualquer coisa material, inclusive ele mesmo, pode ser encontrada ${ }^{9}$. Se queremos questionar a desincorporação da subjetividade, a virtualização e objetivação da corporeidade produzida pelas tecnologias de visualização, um paradigma da corporeidade que leve em conta a experiência subjetiva do corpo é mais adequado do que um paradigma construtivista.

\section{Anatomia fenomenológica do corpo vivido}

Na linha de uma fenomenologia da corporeidade, Drew Leder propõe no seu livro The $A b$ sent Body 10 uma "anatomia fenomenológica do corpo vivido", que possui uma relevância fundamental para a análise da visualização médica do corpo e da qual vale a pena expor os argumentos principais. Frente à maioria dos fenomenólogos da corporeidade, para os quais as análises do corpo vivido têm sua origem no que Merleau-Ponty chamou de "primazia da percepção”, Leder focaliza nas dimensões ausentes e recessivas do corpo vivido, entre elas o interior do corpo, a visceralidade. A presença corporal possui uma natureza paradoxal, apresentando-se ao mesmo tempo como uma presença inescapável e uma ausência fundamental. O corpo constitui a base da experiência humana e, no entanto, recua da experiência direta, ou seja, ele é raramente tematizado de maneira imediata. É um campo organizado no qual determinados órgãos e atividades se destacam enquanto outros recuam. As experiências de ausência corporal encorajam e sustentam, segundo Leder, o paradigma dualista. Este não é algo alheio à experiência vivida, uma concessão a pressupostos ontológicos, como comumente pensamos. Uma opinião também defendida por Arendt 1 (p. 22-3), para quem “ $a$ 
teoria dos dois mundos pertence às falácias metafísicas, mas não teria sobrevivido durante tantos séculos se não correspondesse de modo plausível a alguma experiência básica". Não é incompatível questionar a hegemonia conceitual do dualismo e ao mesmo tempo aproveitar sua verdade experiencial.

A superfície do corpo tende a desaparecer da apreensão temática por ser o lugar desde o qual eu existo no mundo (o ponto zero de todas as orientações), os órgãos da percepção e motilidade, projetados para fora, são transparentes no momento de seu uso. Edmund Husserl 11 cunhou o termo "ponto zero" (Nullpunkt) para descrever o corpo como o "ponto zero" de todas as orientações. Nesse ponto, a maioria dos autores que defendem posições próximas da fenomenologia da corporeidade concordam. Já no final do século XIX, William James e Bergson tinham chamado a atenção para esse aspecto. Para James 12 (p. 284), o corpo ocupa o lugar central no mundo experienciado como "centro de visão, centro de ação, centro de interesse". O corpo é o "centro nevrálgico" (storm centre), "origem das coordenadas". Ele enfatiza uma posição, um ponto de vista, a perspectiva de meu corpo no espaço. A localização do corpo no mundo permite uma "sistematização das coisas com referência a um foco de ação e interesse que se encontra no corpo" 12 (p. 284). "Tudo gira em torno dele e é sentido desde o seu ponto de vista", insiste James 12 (p. 284), “onde o corpo está, é 'aqui'; quando o corpo age é 'agora'; o que o corpo toca é 'isto'; o resto das coisas é 'ali', 'então' e 'aquilo".

Em contraste com a dimensão da superfície corporal, que sobressai e se estende para fora na ação - e que Leder chama de corpo ex-tático (ecstatic body) -, o interior do corpo, a visceralidade, desaparece por estar deslocada da ação, "é uma parte do corpo que não usamos para perceber ou agir sobre o mundo num sentido direto" 10 (p. 53). Ter acesso direto a esse campo interoceptivo constituiria uma distração desnecessária para a ação. Leder 10 denomina o retrocesso da visceralidade de "desaparecimento profundo". Profundo deve ser entendido em um duplo sentido, físico, pois o interior do corpo está protegido pela superfície; e fenomenológico, por não estar disponível à minha apreensão e domínio consciente. O campo interoceptivo, isto é, as sensações dos órgãos internos do corpo, é definido por três características. Apresenta, em primeiro lugar, uma redução qualitativa em relação ao campo exteroceptivo (os cinco sentidos projetados para o mundo). A interocepção não dispõe da multidimensionalidade da exterocepção, o número e variedade de receptores sensoriais são muito inferiores aos da superfície corporal e portanto o repertório de respostas é mais limitado. O interior do corpo possui, em segundo lugar, uma ambigüidade espacial em relação à exterocepção, que faz com que as sensações viscerais careçam da precisão espacial, da localização precisa das sensações cutâneas. Finalmente, a corrente da experiência interoceptiva caracterizase pela descontinuidade espaço-temporal - a maioria dos processos vegetativos acontece em um profundo silêncio -, frente à continuidade espaço-temporal da exterocepção. Assim, “ao contrário da percepção completa do corpo proprioceptivo, nosso corpo interno é marcado por lacunas regionais, órgãos que apesar de serem cruciais para a manutenção da vida não podem ser percebidos somatestesicamente" 10 (p. 43).

\section{Antropologia mínima}

Certas formas de desaparecimento são essenciais para o funcionamento do corpo. Na qualidade de "ser-no-mundo ex-tático/recessivo" (ecstatic/recessive being-in-the-world), o corpo vivido é necessariamente "auto-obliterador" (self-effacing). Ou seja, o que me parece fundamental é que a natureza recessiva do corpo compõe um dos invariantes existenciais e biológicos que moldam a experiência humana 10 . Esses invariantes fazem parte do que poderíamos chamar de uma antropologia mínima. A posição ereta e a assimetria frente/dorso de nosso corpo fazem também parte dessa antropologia mínima. A posição ereta, vertical de nosso corpo (que deve ser permanentemente preservada no campo gravitacional terrestre) e a assimetria entre os movimentos orientados para frente e para trás de nosso corpo são características formadoras de nossa experiência. Essa assimetria natural é constitutiva do campo espaço-temporal, especialmente de seu eixo temporal. Ela é responsável pelo fato de que as ações orientadas para trás sejam geralmente desajeitadas e menos efetivas, e que "a atividade efetiva esteja dirigida para o que se encontra na frente" 9 (p. 118). Daí que ação e percepção ativa se orientem sempre para frente. Quando nos movemos, afirma Todes, "não simplesmente notamos, mas produzimos o campo espaçotemporal ao redor de nós" 9 (p. 49). A antropologia mínima não pode ser dispensada, já que constitui o invariante em torno do qual as variações históricas e culturais se aplicam. "As variações culturais são sempre executadas em cima do espectro de possibilidades apresentadas por nossa estrutura corporal" 10 (p. 3). Não podemos esquecer que os novos avanços bio- 
tecnológicos nas áreas de engenharia genética, próteses, nanotecnologia, robótica, entre outros, podem levar a mudar (se já não estão mudando) essa antropologia. Não é de todo improvável imaginar um futuro não tão distante no qual o que agora consideramos como invariantes biológico-existenciais possam ser alterados. Assim, poderíamos pensar na influência das tecnologias de visualização médica e na insistência em tornar visível e acessível o interior do corpo em relação ao invariante que representa a tendência recessiva da visceralidade. Com certeza, a obsessão crescente com visualizar o interior do corpo deve afetar de uma maneira que ainda não podemos predizer o invariante constituído pela propensão de nosso corpo a se tornar recessivo. Essas alterações constituirão, no entanto, novos invariantes em torno dos quais novas variações culturais serão testadas. Para poder falar de variação precisamos sempre de um invariante, em referência ao qual a variação aparece como tal. É necessário pressupor a não-variabilidade do corpo humano como uma forma para poder avaliar se alguma variação acontece. Para o homem ativo, nos lembra Samuel Todes 9 (p. 71), o corpo é " a condição de possibilidade de que as coisas se mostrem variáveis para ele". Afirmar que tudo varia ou que existe uma infinita variabilidade do corpo como fazem muitos autores, exige um invariante para poder perceber a variação. É a partir de um ponto que não varia que percebo a variação. Esse ponto invariável é o corpo, a estrutura corporal irreversível. Com palavras de Todes 9 (p. 108), “a percepção (awareness) de nosso próprio movimento implica uma mudança penetrante e sistemática de todas as posições circunstanciais em relação à nossa (...). Ao nos movimentarmos transformamos nosso campo de posições perceptuais". O corpo ativo ao se movimentar carrega consigo seu ponto de origem. Ser ativo pressupõe a capacidade de inverter a direção; eu posso me virar e mudar a direção. Todavia, o "senso de direção” permanece constante. Caminho sempre "para frente", mesmo se o que antes estava "à frente" se encontre agora "atrás": "Essa habilidade de inverter sensivelmente a direção, pressupõe, no entanto, um senso de direção invariante (...) em virtude da assimetria funcional da estrutura frente-dorso do corpo" 9 (p. 106).

A variabilidade espacial e temporal é dada pela não-variabilidade de meu corpo ativo. Henri Bergson 13 postula também o corpo como não variável para que a variação apareça como tal. Para o filósofo francês, o corpo é uma imagem, imersa num mundo de imagens, que constitui o mundo material. Como o resto das imagens, ele atua recebendo e devolvendo movimento, e se distingue das outras imagens na capacidade de escolher o tipo de movimento que devolve. A centralidade do corpo determina minha percepção e faz com que as outras imagens se regulem em torno dela, como no giro de um caleidoscópio que muda tudo ao seu redor: “à medida que meu corpo se desloca no espaço, todas as outras imagens variam; a de meu corpo, ao contrário, permanece invariável. Devo portanto fazer dela um centro, ao qual relacionarei todas as outras imagens" 13 (p. 122).

O fato de admitir a existência de uma "antropologia mínima” não nos torna essencialistas ou fundacionalistas, que não levam em conta as variações culturais e sócio-históricas. Drew Leder 10 fala de vetores fenomenológicos, como as estruturas da experiência que possibilitam e orientam o sujeito em determinadas direções sem constituir invariantes. A mão é usada, por exemplo, na maioria das culturas no trabalho e na exploração do mundo, devido a seu elevado grau de plasticidade e sua liberdade de ação, graças à posição ereta e à destreza do polegar. Isto é, nossa estrutura corporal encoraja esse uso da mão, o qual não é, contudo, nem necessário nem invariante. Em determinadas condições se poderia pensar em culturas que realizem numerosas atividades com os pés. Está no campo do imaginável. Existem também formas de desaparecimento que são sócio-histórica e culturalmente condicionadas, as quais dizem respeito à construção social da consciência do corpo. Aí os exemplos são múltiplos, indo desde a percepção da cor da pele em uma sociedade racista, até as formas de desaparecimento experienciadas nos exames médicos, quando o corpo é reduzido a um conjunto de órgãos, ou o estilo "tipicamente feminino" de comportamento corporal, que subestima a força e habilidade física e provoca movimentos tímidos e reativos, não se tratando evidentemente de uma incapacidade biológica. Desaparecimento social pode levar à disfunção biológica como no caso de distúrbios alimentares, anorexia e bulimia, ou vice-versa, quando a disfunção biológica pode levar ao desaparecimento social como acontece com muitos deficientes físicos. Vetores fenomenológicos e formas de desaparecimento social convivem com invariantes biológico-existenciais, tais como o caráter recessivo do interior do corpo.

Se a intencionalidade corporal motora corresponde, segundo Husserl 11, Merleau-Ponty 14, Erwin Straus 15 e outros, à fórmula "eu posso" (caminhar, olhar, apreender), em se tratando do interior do corpo a fórmula mais adequada é "isso pode" (it can) - "isso" podendo ser o co- 
ração, o baço, o pulmão, entre outros -, pois as profundezas corporais desaparecem da percepção, da vontade e da ação, procedendo de modo automático sem minha consciência ou volição. Assim, o "isso pode" do interior do corpo torna-se em "eu devo", isto é, uma dimensão corporal que escapa à minha volição e apreensão consciente e que, no entanto, me impele e constrange. Existe evidentemente espaço para uma certa variação cultural no nível do automatismo e da necessidade que a visceralidade apresenta. Práticas orientais de atenção levam ao aumento de consciência dos processos viscerais, tais como o controle do pulso sangüíneo, do batimento cardíaco e assim por diante. O nível extremo de treinamento exigido para atingir esse controle é uma confirmação (e não uma refutação) da tendência recessiva do interior do corpo em relação à superfície corporal.

\section{Ambivalência ontológica da visceralidade}

Os órgãos internos apresentam uma "ambigüidade ontológica” 16 (p. 101). Eles me pertencem, mas eu também lhes pertenço; são um outro em mim, necessários para minha própria existência. Eles se apresentam como uma "estranheza-própria" (foreign-mineness), usando a expressão de Buytendijk (1974, apud Leder 10, p. 48). O visceral "não se pode propriamente dizer que pertença ao sujeito; é um poder que me atravessa, me vivificando de maneiras que eu realmente nunca desejei nem compreendi" 10 (p. 65). A experiência do corpo vivido combina as perspectivas científicas da terceira pessoa com a descrição fenomenológica em primeira pessoa. Experiencio meu corpo como uma dimensão subjetiva e como um objeto entre os objetos, como Leib e Körper, corpo vivo e corpo vivido. Na língua alemã existem dois termos para expressar esta dualidade: Körper e Leib, designando o primeiro o objeto construído cientificamente e descrito de forma física ou fisicalista, e o segundo a experiência corporal vivenciada. Apesar de já encontrarmos na "Fenomenologia do Espírito” de Hegel o uso dos termos Körper/Leib 16, é o mérito da fenomenologia do corpo de Edmund Husserl 11 e de MerleauPonty 14 ter chamado a atenção e desenvolvido o caráter de reversibilidade do corpo exprimido na diferença corpo vivo/corpo vivido ou ter um corpo e ser um corpo, isto é, entre o corpo sujeito e corpo objeto.

O visceral representa uma dimensão em terceira pessoa (corpo-objeto) à qual não possuo acesso imediato na experiência própria de meu corpo em primeira pessoa (corpo-sujeito). É algo que me habita, que se me impõe e que oblitera outras dimensões, um "alheamentode-dentro" (alienness-from-within), que me impediria de reconhecer meus próprios órgãos se me fossem apresentados. "Estaria na presença de algo estranho e alheio - poderiam esses órgãos se encontrar realmente dentro de mim?" 10 (p. 54). O interior do corpo é unheimlich no sentido de Freud 18 (p. 268), algo estranho/sinistro, que é, ao mesmo tempo, "secretamente familiar" (Heimliche-Heimische). "Heimlich", Freud 18 (p. 250) observa, "é uma palavra cujo significado desenvolve-se na direção de uma ambivalência, até que finalmente coincide com seu oposto, unheimlich. Unheimlich é, de qualquer modo, uma forma de heimlich."

Acredito que o fascínio e o sucesso que possuem as novas tecnologias de visualização do interior do corpo na nossa cultura, para além de sua indiscutível eficácia diagnóstica e terapêutica no campo estritamente biomédico, deve-se ao fato de serem tentativas de lidar com a ambivalência ontológica fundamental e constitutiva do visceral, de transformar o estranho (unheimlich) em familiar (heimlich), de tornar previsível, disponível, acessível uma dimensão da corporeidade que é, por natureza, recessiva e ausente, que se recusa e recua da apreensão direta. O interior do corpo me provoca uma angústia básica de algo que não posso controlar, que escapa à minha apreensão e, no entanto, me habita. A medicina tenta negar, domar, controlar a dimensão fenomenológica do visceral por meio das tecnologias de imageamento. O visceral ameaça o projeto biomédico e cultural do conhecimento objetivo, de objetificação do corpo vivido e desincorporação da subjetividade, constitutivo da história das tecnologias de visualização. Essas tecnologias, no entanto, apenas fornecem um conhecimento objetivo, um modo de auto-apreensão indireta do interior do corpo, o qual retrocede da percepção direta, da experiência subjetiva. "As ausências que assombram minhas profundezas corporais não são obliteradas por essas manobras reflexivas" 10 (p. 44). Existe então, uma "não-coincidência fenomenológica” 10 (p. 44) entre o corpo-objeto apresentado pelas tecnologias de imageamento e o corpo-sujeito ou corpo vivido. As exposições diretas do interior do corpo pelas tecnologias médicas ou por procedimentos cirúrgicos, afirma Leder 10 (p. 51), “são ainda 'indiretas' em um sentido fenomenológico. O paciente utiliza o corpo de outro como um conduto indireto de percepção e controle".

A dimensão visceral do corpo deve ser acrescentada ao inconsciente corporal, enraizado 
na nossa resposta sensório-motora ao mundo, ao qual a fenomenologia de Merleau-Ponty 14 se refere como uma maneira de evitar os paradoxos apresentados em noções reificadas e mentalistas do inconsciente. Nesse contexto, vale a pena lembrar que o ano de 1895 marca não apenas a coincidência do nascimento do cinema e da descoberta dos raios X, como vários historiadores têm reconhecido, dando lugar a uma profícua linha de investigação na interseção da historia da medicina e das artes visuais 19,20. Essa data registra também, como Lippit 21 nos lembra, o nascimento da psicanálise, pois em 1895, Freud 22 sonhou com Irma, que lhe revelaria o segredo dos sonhos, fornecendo-lhe uma oportunidade de observar o aparelho psíquico em movimento, de visualizar o inconsciente. Nascem, deste modo, em 1895 três "fenomenologias do interior": raios X, cinema e psicanálise, "tentando expor as anatomias do corpo, do movimento e da psique respectivamente. As três tecnologias não só mudaram o estatuto do referente ou o documento de interioridade, elas também transformaram os termos nos quais tais interioridades eram contempladas" 21 (p. 42). Na virada do século XIX para o $\mathrm{XX}$, a anatomia do psiquismo é correlata das novas possibilidades de anatomizar e visualizar o interior do corpo. O inconsciente visceral aparece como dimensão inevitável do inconsciente tout court. Trata-se de um novo capítulo de uma filiação característica de nossa cultura ocidental, a qual estabelece uma estreita vinculação entre o interior do corpo e a dimensão psicológica da interioridade ou da privacidade. É por isso que o conhecimento do interior do corpo representa uma metáfora eficaz do conhecimento de si, e não apenas porque a certeza de nossa própria morte (o ser-para-a-morte heideggeriano) nos é confirmada pela visualização de nosso esqueleto. Para o Heidegger de Ser e Tempo 23, a antecipação e a certeza da morte (Vorlaufen zum Tode) constituem a chave para uma existência mais autêntica, a possibilidade mais própria (eigenste) do Dasein, seu "próprio ser si mesmo" (eigentliches Selbstsein). A reflexão heideggeriana é apenas um capítulo da longa história da obsessão da filosofia pela morte no Ocidente. A meditação ou o exercício da morte (a meletê thanatou da tradição grecolatina) como atualização a morte em vida é uma forma de autoconhecimento. Ela constitui "uma certa maneira de tomar consciência de si mesmo a partir de esse ponto de vista (...) da morte ou dessa atualização da morte na nossa vida" 24 (p. 458). As tecnologias de imageamento do corpo funcionam também como uma antecipação da morte, vejo meu próprio cadáver em vida, obrigando-me a encarar a realidade de minha morte.

O conhecimento do interior do corpo e o conhecimento de si coexistem em nossa cultura, confirmado pela história da dissecação anatômica e das tecnologias de visualização do corpo. Assim, durante os séculos XVI e XVII, o chamado "século visceral", o interior do corpo está comprometido na produção da interioridade mental e espiritual, da experiência individual privada, numa cultura na qual a abertura do corpo é central na produção de conhecimento 25,26,27. O preceito délfico de "conhece-te a ti mesmo" torna-se o conhecimento do homem anatomizado. Apesar da relação entre identidade pessoal e materialidade no mundo pré-cartesiano preceder a separação do vocabulário da fisiologia médica e dos humores do vocabulário da psicologia individual, essa ligação, no entanto, continua vigente até nossos dias. O fascínio e a angústia exercidos pela possibilidade de visualizar as entranhas resulta incompreensível sem essa vinculação. Uma ligação que evidencia também o comprometimento da medicina com o estatuto antropológico do homem na cultura ocidental, constatado por Foucault 28 em relação à anatomia patológica, a qual, introduzindo a morte no pensamento médico, possibilitou a constituição do sujeito moderno como sujeito e objeto de conhecimento a partir da experiência fundamental da finitude. Medicina e filosofia coincidem no Ocidente na fixação com a morte e na escolha do cadáver como o modelo privilegiado de corpo. Na biomedicina, especificamente na tradição anatômica e nas tecnologias de imageamento, o cadáver possui uma primazia epistemológica. Na filosofia, ele representa desde Descartes o modelo do corpo vivido.

Se para Foucault 29 a dimensão biopolítica da medicina reside no seu poder normalizador, e se o totalitarismo representa o paroxismo do biopoder por reduzir o corpo a uma coisa inanimada, res extensa ou cadáver 30,31 , podemos dizer que a medicina compartilha com o biopoder totalitário o pressuposto da redução da vida em um sentido complexo que inclui as dimensões sócio-culturais e históricas à vida orgânica, e do corpo ao cadáver. Nos campos de concentração os indivíduos eram reduzidos a “cadáveres vivos" mediante a aniquilação da pessoa jurídica, da pessoa moral do indivíduo e da identidade pessoal, eliminando sua espontaneidade. A descrição fenomenológica de Hannah Arendt 30,31 da fabricação de cadáveres no campo de concentração assemelha-se no nível biopolítico à manufatura de corpos com fins cirúrgicos - tal como descrita no inte- 
ressante texto de Hirschhauer 32 -, ou à redução do corpo a uma passividade cadavérica em diversos exames médicos, nos quais, "o paciente é solicitado a assumir uma postura cadavérica, plano, passivo, nu, mudo. Todo ritual e contexto servem para reduzir o corpo vivo a alguma coisa quase morta. A identidade pessoal é removida assim como o paciente é removido de seu ambiente habitual, suas atividades e até mesmo de suas roupas (...). O paciente é colocado em uma posição de passividade cadavérica"
10 (p. 22). Essa comparação não tem o intuito de provocar. É obvio que se trata de dois tipos diametralmente opostos de reducionismo do corpo vivo ao cadáver, com conseqüências antagônicas. No caso da biomedicina, o reducionismo é metodológico, isto é, para fins de diagnóstico e tratamento, enquanto o reducionismo biopolítico é ontológico. Trata-se de uma questão fundamental que percorre a história da tradição anatômica e sobre a qual não podemos deixar de refletir.

\section{Resumo}

Este artigo tem como objetivo analisar a dimensão fenomenológica do interior do corpo em face do sucesso das novas tecnologias de visualização médica para além do âmbito estritamente biomédico. As novas tecnologias estão contribuindo para a desincorporação da subjetividade e para a virtualização e objetivação da corporeidade, ignorando a dimensão subjetiva constitutiva do corpo vivido. O artigo pretende investigar essa dimensão fundamental da corporeidade irredutível à sua apreensão pela visualização médica.

Desenvolvimento Tecnológico; Diagnóstico por Imagem; Técnicas de Diagnóstico e Procedimentos 


\section{Referências}

1. Arendt H. The life of the mind. v. 1. Thinking. New York: Harcourt Brace \& Company; 1978.

2. Ortega F. Da ascese à bio-ascese, ou do corpo submetido à submissão ao corpo. In: Rago M, Orlandi L, Veiga-Neto A, organizadores. Imagens de Foucault e Deleuze: ressonâncias nietzschianas. Rio de Janeiro: DP\&A; 2002. p. 139-73.

3. Ortega F. Modificações corporais e bioidentidades. Revista de Comunicação e Linguagens 2004; 33:247-63.

4. Foucault M. La volonté de savoir. Paris: Gallimard; 1984.

5. Duden B. The woman beneath the skin: a doctor's patients in eighteenth-century Germany. Cambridge: Harvard University Press; 1997.

6. Petersen A. What's at stake? Anatomical constructions of the body. http://central.com.au/artmed/ papers/peterse.html (acessado em 10/Mai/2004).

7. Butler J. Bodies that matter: on the discursive limits of sex. New York: Routledge; 1993.

8. Butler J. Gender trouble: feminism and the subversion of identity. New York: Routledge; 1990.

9. Todes S. Body and world. Cambridge: The MIT Press; 2001.

10. Leder D. The absent body. Chicago/London: The University of Chicago Press; 1990.

11. Husserl E. Idées directrices pour une phénoménologie et une philosophie phénoménologique pures. Livre second: recherches phénoménologiques pour la constitution. Paris: PUF; 1996.

12. James W. The experience of activity. In: McDermott J, editor. The writings of William James. New York: The Modern Library; 1968. p. 277-91.

13. Bergson H. Matéria e memória. São Paulo: Martins Fontes; 1999.

14. Merleau-Ponty M. Phénoménologie de la perception. Paris: Gallimard; 1987.

15. Straus E. Du sens des sens - contribiton à l'étude des fondements de la psychologie. Grenoble: Éditions Jérôme Million, 2000.

16. Young K. Presence in the flesh: the body in medicine. Cambridge: Harvard University Press; 1997.

17. Russon J. The self and its body in Hegel's 'Phenomenology of Spirit'. Toronto/Buffalo/London: University of Toronto Press; 2001.
18. Freud S. Studienausgabe. v. IV. Psychologische schriften. Frankfurt am Main: Fischer Verlag; 2000.

19. Cartwright L. Screening the body. Tracing medicine's visual culture. Minneapolis: University of Minnesota Press; 1987.

20. Curtis S. Still/moving: digital imaging and medical hermeneutics. In: Rabinovitz L, Geil A, editors. Memory bytes: history, technology, and digital culture. Durham: Duke University Press; 2004.

21. Lippit A. Phenomenologies of the surface: radiation-body-image. Qui Parle: Literature, Philosophy, Visual Arts, History 1996; 9:31-50.

22. Freud S. Studienausgabe. v. II. Frankfurt am Main: Fischer Verlag; 2000.

23. Heidegger M. Sein und zeit. Tübingen: Max Niemeyer; 1986.

24. Foucault M. L'herméneutique du sujet: cours au Collège de France 1981-1982. Paris: Seuil/Gallimard; 2001.

25. Hillman D. Hamlet, Nietzsche, and visceral knowledge. In: O'Donovan-Anderson M, editor. The incorporated self: interdisciplinary perspectives on embodiment. Lanham: Rowman \& Littlefield Publishers; 1996. p. 93-110.

26. Hillman D. Visceral knowledge. Shakespeare, skepticism, and the interior of the early modern body. In: Hillman D, Mazzio C, editors. The body in parts. Fantasies of corporeality in early modern Europe. New York/London: Routledge; 1997. p. 81-105.

27. Sawday J. The body emblazoned: dissection and the human body in renaissance culture. London/ New York: Routledge; 1996.

28. Foucault M. O nascimento da clínica. Rio de Janeiro: Forense Universitária; 1994.

29. Foucault M. Dits et écrits. v. III. Paris: Gallimard; 1994.

30. Arendt H. The concentration camps. Partisan Review 1948; 15:752-9.

31. Arendt H. The origins of totalitarianism. New York: Harcourt Brace \& Company; 1979.

32. Hirschhauer S. The manufacture of bodies in surgery. Soc Stud Sci 1991; 21:279-319.

Recebido em 03/Dez/2004

Versão final reapresentada em 25/Abr/2005

Aprovado em 20/Mai/2005 